\title{
How Temperature and Photosynthetically Active Radiation Impact the Green Synthesis of Silver Nanoparticles Using Aqueous Extracts of Mentha Leaves?
}

\author{
Carolina Roberte Oliveira ${ }^{1}$ (D), Luciano Paulino Silva ${ }^{2, *(\mathbb{D})}$ \\ 1 University of Brasilia, IB, Brasília-DF, 70910-900, Brazil; carolinaroberte@ gmail.com (C.R.O.); \\ 2 Embrapa Genetic Resources and Biotechnology, Brasília-DF, 70770-917, Brazil; luciano.paulino@embrapa.br (L.P.S.); \\ * Correspondence: luciano.paulino@embrapa.br (L.P.S.);
}

Scopus Author ID 7202197642

Received: 15.08.2021; Revised: 22.09.2021; Accepted: 26.09.2021; Published: 16.10.2021

\begin{abstract}
Green synthesis highlights sustainable methods to produce silver nanoparticles (AgNPs). Here, extracts from fresh and lyophilized Mentha leaves produced AgNPs when performing reactions in the dark at $25^{\circ} \mathrm{C}$ or $75^{\circ} \mathrm{C}$; also under photosynthetically active radiation (PAR) at $25^{\circ} \mathrm{C}$ aiming to compare hydrothermal and photochemical methods. AgNPs formation was spectrophotometrically monitored and characterized by dynamic light scattering (DLS) and Zeta potential (ZP). The most polydisperse AgNPs suspension was synthesized at $25^{\circ} \mathrm{C}$ (dark), presenting polydispersity index (PdI) of $0.574 \pm 0.061$, and exhibited the lowest hydrodynamic diameter (HD) of $44.34 \pm 1.60 \mathrm{~nm}$. In contrast, the highest $\mathrm{HD}$ was $80.15 \pm 2.88 \mathrm{~nm}$ to $\mathrm{AgNPs}$ produced at $25^{\circ} \mathrm{C}$ with $\mathrm{PAR}$ which exhibited $\mathrm{ZP}$ of $27.8 \pm 0.7 \mathrm{mV}$. The lowest polydisperse suspension was produced at $75^{\circ} \mathrm{C}$ (dark), presenting PdI of $0.369 \pm 0.009$ and $\mathrm{ZP}$ of $-12.8 \pm 0.6 \mathrm{mV}$. Concluding, we compared reliable green synthesis' methods to determine which would efficiently produce AgNPs using Mentha leaves.
\end{abstract}

Keywords: green nanotechnology; green synthesis; hydrothermal method; nanoparticles; optical materials and properties; photochemical method; photocorrelation spectroscopy; silver nanoparticles; spectroscopy; zeta potential.

(C) 2021 by the authors. This article is an open-access article distributed under the terms and conditions of the Creative Commons Attribution (CC BY) license (https://creativecommons.org/licenses/by/4.0/).

\section{Introduction}

Silver nanoparticles (AgNPs) exhibit unique physicochemical and biological properties dependent on composition and size [1-6]. AgNPs are used for controlling microorganisms, diagnosis, catalysts, and others. Choosing a green route to synthesize AgNPs means generating less harmful residues and safer products compared to other routes $[7,8]$.

Plants are commonly used for green synthesis due to phytochemicals, and selected species meet criteria like: be easy to grow and harvest; cheap to cultivate; low maintenance to feasible scale-up; and provide reducing and stabilizing agents [9,10]. Plants from the Lamiaceae family meet such criteria with about $\sim 5,000$ species, including those belonging Mentha genus [11]. These species are widespread and contain antioxidant phytochemicals such as menthol, limonene, linalool, and others [12].

There are several methods to greenly-synthesize AgNPs using Mentha [13-17]. Temperature is a well-explored parameter as higher temperatures speed up the formation and modulate properties of AgNPs synthesized using plant extracts [18]. Another fashion is a photo-induced route, in which irradiating light boosts AgNPs synthesis [19]. However, 
comparisons between both strategies are scarce, particularly when considering the use of Mentha extracts. In addition, there is no consensus about the ideal state for plant materials (e.g., fresh or dry powder samples). Thus, the present study investigated whether fresh or lyophilized Mentha leaves promoted AgNPs' synthesis (AgNPs-F and AgNPs-L, respectively) and compared the effects of temperature in a hydrothermal method and photosynthetically active radiation (PAR) in a photochemical method.

\section{Materials and Methods}

\subsection{Mentha extract.}

Mentha (Mentha $\times$ villosa Huds.) leaves obtained from the local market were stored at $-20^{\circ} \mathrm{C}$. Leaves were weighed and washed with $400 \mu \mathrm{L}$ of Extran in $1.2 \mathrm{~L}$ of tap water followed by distilled water washing. Part of this material was lyophilized. For each $1 \mathrm{~g}$ of cut leaves, 10 $\mathrm{mL}$ of ultrapure water were boiled 2 min to prepare the aqueous extracts that were further qualitatively filtered.

\subsection{Synthesis of silver nanoparticles.}

Three reaction systems were incubated on glass tubes: $\mathrm{AgNO}_{3}$ control $(50 \mu \mathrm{L}$ of ultrapure-water in $4950 \mu \mathrm{L}$ of $\left.1 \mathrm{mM} \mathrm{AgNO}_{3}\right), \mathrm{AgNO}_{3}$ with fresh leaves extract $(50 \mu \mathrm{L}$ of extract from fresh leaves in $4950 \mu \mathrm{L}$ of $\left.1 \mathrm{mM} \mathrm{AgNO}_{3}\right)$, and extract control (50 $\mu \mathrm{L}$ of extract from fresh leaves in $4950 \mu \mathrm{L}$ of ultrapure-water). Three additional tubes were prepared similarly but with plant extracts produced from lyophilized leaves. All reactions were prepared in triplicates and incubated for $2.5 \mathrm{~h}$ : one was incubated in a water-bath at $75^{\circ} \mathrm{C}$ in the dark; the second incubated under PAR at $25^{\circ} \mathrm{C}$, and the third incubated in the dark at $25^{\circ} \mathrm{C}$.

\subsection{Physicochemical characterization.}

AgNPs' formations were monitored by UV-Vis at $450 \mathrm{~nm}$. Aliquots were taken from reactions and analyzed every $30 \mathrm{~min}$. Formation kinetics of AgNPs was obtained by the equation is $b=\sum(\boldsymbol{x}-\overline{\boldsymbol{x}})(\boldsymbol{y}-\overline{\boldsymbol{y}}) / \sum(\boldsymbol{x}-\overline{\boldsymbol{x}})^{2}$, in which "b" represents the slope of linear regression $=$ (absorption at time 0.5 :absorption at time $2.5 ; 0,5: 2,5)$; " $x$ " represents the absorption at time 0.5; and "y" represents absorption at time 2.5;0,5:2,5. Samples were also analyzed by DLS and electrophoretic mobility for characterization of HD (Z-average) and PdI, and $\mathrm{ZP}$, respectively, at $25^{\circ} \mathrm{C}$ (triplicates-10 runs).

\section{Results and Discussion}

\subsection{UV-Vis and formation rate.}

It is well-established that color change from transparent to dark yellow or brown is indicative of metallic ion reduction, as well as the nucleation and formation of AgNPs [4,6,18]. Color variation in AgNPs synthesis reactions is explained by the surface plasmon resonance phenomenon in which conduction electrons oscillate when stimulated by polarized lights [6]. Syntheses were monitored by UV-Vis to confirm the formation of AgNPs (Figure 1). Even though AgNPs-L had higher absorbance at the first hour of reaction, reactions incubated in the dark at $75^{\circ} \mathrm{C}$ and AgNPs-F had the highest absorbance at the end-point. This indicates that fresh 
leaves reduced more efficiently a larger amount of Ag+ than lyophilized leaves, yielding more AgNPs.

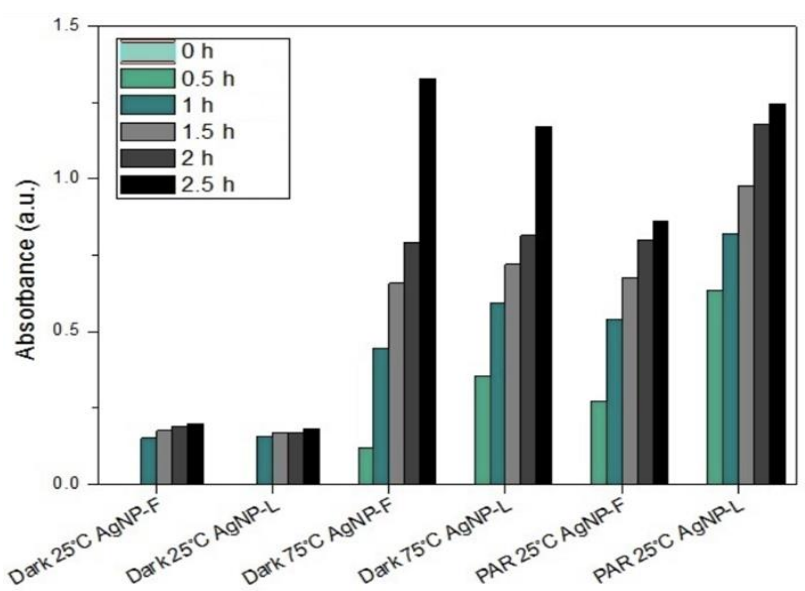

Figure 1. UV-Vis spectra of the synthesis reactions with fresh (AgNP-F) or lyophilized (AgNP-L) Mentha leaf extracts under dark or PAR conditions and at $25^{\circ} \mathrm{C}$ or $75^{\circ} \mathrm{C}$

The kinetics of AgNPs formation was calculated by linear regression slope of absorption curve to obtain an indication of the fastest method leading to the nucleation and growth (Figure 2). AgNPs-F synthesized in the dark at $75^{\circ} \mathrm{C}$ had the fastest nucleation and growth rate. Since nucleation and growth were not distinguishable events, they were defined as formation rates. AgNPs-L synthesized in the dark at $25^{\circ} \mathrm{C}$ showed the slowest formation rate. Probably, once phytochemicals are more concentrated with less amount of water, they may have interacted more with the silver ions and, consequently, this may have delayed its reduction and formation of AgNPs. In addition, the delay wasn't pronounced in the suspension of AgNPs-L synthesized in the dark at $75^{\circ} \mathrm{C}$, probably because of the high temperature, which in this case contributed to speeding up the process. Thus, AgNPs synthesized with higher temperatures were formed faster, while those non-exposed to neither high temperatures nor PAR showed a slower formation rate.

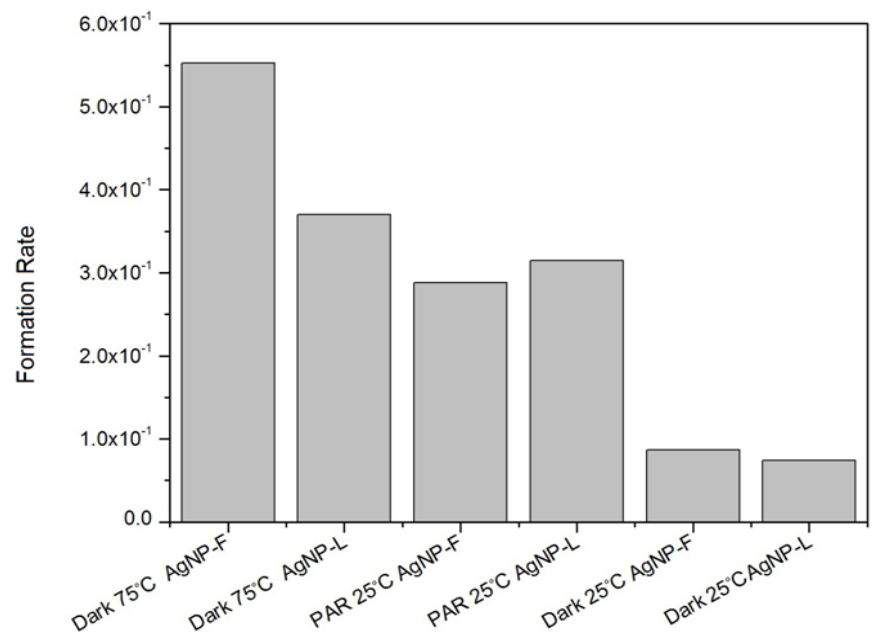

Figure 2. Formation rate of the AgNPs using fresh (AgNP-F) or lyophilized (AgNP-L) Mentha leaf extracts under dark or PAR conditions and at $25^{\circ} \mathrm{C}$ or $75^{\circ} \mathrm{C}$.

\subsection{HDs, PdIs, and ZPs.}

AgNPs with smaller HD were AgNPs-F incubated in the dark at $25^{\circ} \mathrm{C}$, which contrasted with HD of AgNPs-F incubated in the presence of PAR (Table 1). Seemly, there is no recognized pattern in the production of larger or smaller AgNPs depending only on the 
synthesis method (Table 1). What may have happened is that suspension exposed to $75^{\circ} \mathrm{C}$ enhanced reduction of silver ions by fresh leaves extract and, as reaction didn't occur fast (Figure 1) in first hours; AgNPs nucleated, grew slower, and apparently didn't cluster as the AgNPs exposed to PAR. Latter reactions occurred faster especially in the first hours, and presented a higher PdI, indicating that suspension of AgNPs was also polydisperse. It was previously seen that the higher the reaction's temperature, the higher the adsorption rate of silver ions, which facilitate synthesis and result in larger-size particles [20]. A similar approach using M. piperita obtained AgNPs with an average diameter of $75 \mathrm{~nm}$, which isn't far from our results [21]. Results may be similar because both aqueous extracts used in reactions were obtained from Mentha species, despite possible different phytochemical compositions.

PdI obtained for all samples is characteristic of AgNPs synthesized through green synthesis, in which agglomeration and growth are not controlled. It is possible to observe that some characteristics of nanomaterials, like shape and stability, vary a lot between different routes [22]. Li and Kaner [22] also observed that nanoparticles produced at high temperatures evolve to homogeneous nuclei before the growth occurs, decreasing the chance of heterogeneous size dispersion. Another interesting strategy towards producing uniform AgNPs was recently proposed by Nouri et al. [13]. They synthesized AgNPs using M. aquatica leaves extract by ultrasonic process and obtained monodisperse and smaller structures when compared to the hydrothermal method [13]. In the future, combinations of hydrothermal, ultrasonic, and even photonic methods will prove feasible, aiming to optimize the formation of AgNPs.

Overall obtained AgNPs showed ZPs ranging from -12.8 to $-27.8 \mathrm{mV}$ indicative of incipient colloidal stability (Table 1). Negative ZP means that negatively charged groups mainly establish capping.

Table 1. DLS and ZP results of AgNPs synthesized with Mentha fresh (AgNP-F) or lyophilized (AgNP-L) leaf extracts. Values refer to the mean and standard deviation of three analyses.

\begin{tabular}{c|c|c|c|c}
$\begin{array}{c}\text { Condition and } \\
\text { Temperature }\end{array}$ & Sample & HD $(\mathbf{n m})$ & PdI & ZP $(\mathbf{m V})$ \\
\hline Dark at $25^{\circ} \mathrm{C}$ & AgNP-F & $44.34 \pm 1.63$ & $0.574 \pm 0.061$ & $-20.9 \pm 0.8$ \\
\hline Dark at $25^{\circ} \mathrm{C}$ & $\mathrm{AgNP}-\mathrm{L}$ & $78.09 \pm 2.30$ & $0.484 \pm 0.005$ & $-18.9 \pm 0.5$ \\
\hline Dark at $75^{\circ} \mathrm{C}$ & $\mathrm{AgNP}-\mathrm{F}$ & $71.21 \pm 9.36$ & $0.485 \pm 0.138$ & $-25.6 \pm 0.6$ \\
\hline Dark at $75^{\circ} \mathrm{C}$ & $\mathrm{AgNP}-\mathrm{L}$ & $67.19 \pm 0.95$ & $0.369 \pm 0.009$ & $-12.8 \pm 0.6$ \\
\hline PAR at $25^{\circ} \mathrm{C}$ & $\mathrm{AgNP}-\mathrm{F}$ & $80.15 \pm 2.88$ & $0.488 \pm 0.046$ & $-27.8 \pm 0.7$ \\
\hline PAR at $25^{\circ} \mathrm{C}$ & $\mathrm{AgNP}-\mathrm{L}$ & $56.86 \pm 2.41$ & $0.525 \pm 0.011$ & $-26.6 \pm 0.8$
\end{tabular}

$\mathrm{HD}=$ Hydrodynamic Diameter; PdI = Polydispersity Index; ZP = Zeta Potential; PAR = Photosynthetically Active Radiation; AgNP-F = Fresh leaf extract; AgNP-L = Lyophilized leaf extract.

\section{Conclusions}

In conclusion, it isn't necessary to lyophilize Mentha leaves to synthesize AgNPs if the fresh extract is prepared and used consecutively. Lyophilization would represent one additional step, while the use of fresh extracts could be more practical, cost-effective, eco-friendly, and facile. Along with the investigation mentioned above, we compared two green syntheses methods to determine which one would faster produce AgNPs. The method chosen for being the most reliable followed synthesis reaction in the dark at $75^{\circ} \mathrm{C}$ with fresh Mentha leaves. This method was chosen since it presents the highest formation rate. Further, we expect to investigate phytochemicals of different species/hybrids, correlating their compounds with the formation of AgNPs. Finally, it is essential to investigate which green synthesis' methods require less energy and time to take place, aiming to optimize sustainable processes. 


\section{Funding}

This research was funded by CAPES, grant numbers 23038.019088/2009-58 and 001; CNPq, grant numbers 311825/2021-4, 307853/2018-7, 408857/2016-1, 306413/2014-0, and 563802/2010-3; Embrapa, grant numbers 10.20.03.009.00.00, 23.17.00.069.00.02, 13.17.00.037.00.00, 21.14.03.001.03.05, 13.14.03.010.00.02, 12.16.04.010.00.06, 22.16.05.016.00.04, and 11.13.06.001.06.03; FAPDF, grant number 193.001.392/2016.

\section{Acknowledgments}

We thank Dr. Vera Lúcia Perussi Polez for providing us with Mentha.

\section{Conflicts of Interest}

The authors declare no conflict of interest. The funders had no role in the study's design, in the collection, analyses, or interpretation of data, in the writing of the manuscript, or in the decision to publish the results.

\section{References}

1. Ahmed, S.; Ahmad, M.; Swami, B.L.; Ikram, S. A review on plants extract mediated synthesis of silver nanoparticles for antimicrobial applications: A green expertise. Journal of Advanced Research 2016, 7, 17-28, https://doi.org/10.1016/j.jare.2015.02.007.

2. Vijayakumar, S.; Divya, M.; Vaseeharan, B.; Chen, J.; Biruntha, M.; Silva, L.P.; Durán-Lara, E.F.; Shreema, K.; Ranjan, S.; Dasgupta, N. Biological compound capping of silver nanoparticle with the seed extracts of blackcumin (Nigella sativa): A potential antibacterial, antidiabetic, anti-inflammatory, and antioxidant. Journal of Inorganic and Organometallic Polymers and Materials 2021, 31, 624-635, https://doi.org/10.1007/s10904-020-01713-4.

3. Neto, L.A.A.; Pereira, T.M.; Silva, L.P. Evaluation of behavior, growth, and swarming formation of Escherichia coli and Staphylococcus aureus in culture medium modified with silver nanoparticles. Microbial Pathogenesis 2020, 149, 104480, https://doi.org/10.1016/j.micpath.2020.104480.

4. Pupe, J.M., Silva, L.P. Modulation of physico-chemical and biological properties of silver nanoparticles synthesized using aqueous extract of flamboyant (Delonix regia var. flavida, Fabaceae) seeds. Journal of Cluster Science 2021, 32, 1053-1060, https://doi.org/10.1007/s10876-020-01871-y.

5. Araujo, T.F.; Pereira, T.M.; Araujo Neto, L.A.; Bonatto, C.C.; Silva, L.P. Enzymatic browning modulates properties of silver nanoparticles produced with banana peel extract. Journal of Inorganic and Organometallic Polymers and Materials 2020, 30, 3702-3708, https://doi.org/10.1007/s10904-020-01510-z.

6. Pereira, T.M.; Polez, V.L.P.; Sousa, M.H.; Silva, L.P. Modulating physical, chemical, and biological properties of silver nanoparticles obtained by green synthesis using different parts of the tree Handroanthus heptaphyllus (Vell.) Mattos. Colloid and Interface Science Communications 2020, 34, 100224, https://doi.org/10.1016/j.colcom.2019.100224.

7. Garibo, D.; Borbón-Nuñez, H.A.; de León, J.N.D.; Mendoza, E.G.; Estrada, I.; Toledano-Magaña, Y.; Tiznado, H.; Ovalle-Marroquin, M.; Soto-Ramos, A.G.; Blanco, A.; Rodríguez, J.A.; Romo, O.A.; ChávezAlmazán, L.A.; Susarrey-Arce, A. Green synthesis of silver nanoparticles using Lysiloma acapulcensis exhibit high-antimicrobial activity. Scientific Reports 2020, 10, 12805, https://doi.org/10.1038/s41598-020-69606-7.

8. Zhang, H.; Chen, S.; Jia, X.; Huang, Y.; Ji, R.; Zhao, L. Comparation of the phytotoxicity between chemically and green synthesized silver nanoparticles. Science of The Total Environment 2021, 752, 142264, https://doi.org/10.1016/j.scitotenv.2020.142264.

9. Chand, K.; Cao, D.; Fouad, D.E.; Shah, A.H.; Dayo, A.Q.; Zhu, K.; Lakhan, M.N.; Dong, S. Green synthesis, characterization and photocatalytic application of silver nanoparticles synthesized by various plant extracts. Arabian Journal of Chemistry 2020, 13, 8248-8261, https://doi.org/10.1016/j.arabjc.2020.01.009.

10. Silva, L.P.; Pereira, T.M.; Bonatto, C.C. Chapter 7 - Frontiers and perspectives in the green synthesis of silver nanoparticles. In Micro and Nano Technologies, Green Synthesis, Characterization and Applications of 
Nanoparticles, 1st ed.; Shukla, A.K., Iravani, S., Eds.; Elsevier: Amsterdam, The Netherlands 2019, 1, 137164, https://doi.org/10.1016/B978-0-08-102579-6.00007-1.

11. Saberiyan Sani, M.N.; Sayadi Anari, M.H. Study on the effect of rainfall level on the size of silver nanoparticles synthesized by plants of the Lamiaceae family in different regions of Iran. International Journal of New Chemistry 2018, 5, 103-112, https://doi.org/10.22034/ijnc.2018.32976.

12. Cappellari, L.D.R.; Santoro, M.V.; Schmidt, A.; Gershenzon, J.; Banchio, E. Improving phenolic total content and monoterpene in Mentha $\mathrm{x}$ piperita by using salicylic acid or methyl jasmonate combined with Rhizobacteria inoculation. International Journal of Molecular Sciences 2020, 21, 50, https://doi.org/10.3390/ijms21010050.

13. Nouri, A.; Yaraki, M.T.; Lajevardi, A.; Rezaei, Z.; Ghorbanpour, M.; Tanzifi, M. Ultrasonic-assisted green synthesis of silver nanoparticles using Mentha aquatica leaf extract for enhanced antibacterial properties and catalytic activity. Colloid and Interface Science Communications 2020, 35, 100252, https://doi.org/10.1016/j.colcom.2020.100252.

14. Javed, B.; Nadhman, A. Optimization, characterization and antimicrobial activity of silver nanoparticles against plant bacterial pathogens phyto-synthesized by Mentha longifolia. Materials Research Express 2020, 7, 085406, https://doi.org/10.1088/2053-1591/abaf19.

15. Gholami, M.; Azarbani, F.; Hadi, F. Silver nanoparticles synthesised by using Iranian Mentha pulegium leaf extract as a non-cytotoxic antibacterial agent. Materials Technology 2021, 1-9, https://doi.org/10.1080/10667857.2021.1906390.

16. Javed, B.; Mashwani, Z.U.R. Phytosynthesis of colloidal nanosilver from Mentha longifolia and Mentha arvensis: Comparative morphological and optical characterization. Microscopy Research and Technique 2020, 83, 1299-1307, https://doi.org/10.1002/jemt.23518.

17. Javed, B.; Nadhman, A.; Razzaq, A. One-pot phytosynthesis of nano-silver from Mentha longifolia L.: their characterization and evaluation of photodynamic potential. Materials Research Express 2020, 7, 055401, https://doi.org/10.1088/2053-1591/ab903b.

18. Bonatto, C.C.; Silva, L.P. Higher temperatures speed up the growth and control the size and optoelectrical properties of silver nanoparticles greenly synthesized by cashew nutshells. Industrial Crops and Products 2014, 58, 46-54, https://doi.org/10.1016/j.indcrop.2014.04.007.

19. Abo-Elmagd, R.A.; Hussein, M.H.; Hamouda, R.A.; Shalan, A.E.; Abdelrazak, A. Statistical optimization of photo-induced biofabrication of silver nanoparticles using the cell extract of Oscillatoria limnetica: insight on characterization and antioxidant potentiality. RSC Advances 2020, 10, 44232-44246, https://doi.org/10.1039/D0RA08206F.

20. Gurunathan, S.; Kalishwaralal, K.; Vaidyanathan, R.; Venkataraman, D.; Pandian, S.R.K.; Muniyandi, J.; Hariharan, N.; Eom, S.H. Biosynthesis, purification and characterization of silver nanoparticles using Escherichia coli. Colloids and Surfaces B: Biointerfaces 2009, 74, 328-335, https://doi.org/10.1016/j.colsurfb.2009.07.048.

21. Barbinta-Patrascu, M.E.; Ungureanu, C.; Iordache, S.M.; Iordache, A.M.; Bunghez, I.; Ghiurea, M.; Badea, N.; Fierascu, R.; Stamatin, I. Eco-designed biohybrids based on liposomes, mint-nanosilver and carbon nanotubes for antioxidant and antimicrobial coating. Materials Science and Engineering C 2014, 39, 177-185, https://doi.org/10.1016/j.msec.2014.02.038/

22. Li, D.; Kaner, R.B. Shape and aggregation control of nanoparticles: Not shaken, not stirred. Journal of the American Chemical Society 2006, 128, 968-975, https://doi.org/10.1021/ja056609n. 